\title{
STUDY ON THE MECHANICAL PROPERTIES OF PALM KERNEL FIBRE REINFORCED EPOXY AND POLY-VINYL ALCOHOL (PVA) COMPOSITE MATERIAL
}

\author{
Obiukwu Osita ${ }^{1, a^{*}}$, Opara Ignatius ${ }^{2, b}$, Udeani Henry ${ }^{3, c}$ \\ ${ }^{1,2,3}$ Department of Mechanical Engineering, \\ School Of Engineering and Engineering Technology, \\ Federal University of Technology, Owerri, Imo State, Nigeria. \\ aobiukwu@futo.edu.ng, bobinech@yahoo.com, cobinech@gmail.com
}

Keywords: natural palm kernel fibre, poly-vinyl alcohol (PVA), epoxy, tensile test, impact test, flexural and hardness test.

\begin{abstract}
The goal of this paper is to determine the mechanical properties of a proposed combined polymer composite which consist of a poly-vinyl alcohol (PVA) matrix and palm kernel fibre reinforced with epoxy. The influence of fibres volume on the mechanical properties of the composites was also evaluated. Composites with volumetric amounts of palm kernel fibre up to 12 $\%$ were fabricated and they were arranged in randomly oriented discontinues form. Tensile, impact, flexural and hardness tests were carried out to determine the characteristics of material. The acquired results show that the tensile modulus changes with the fibre content. The strength of coconut fibre reinforced composites tends to decrease with the amount of fibre which indicates ineffective stress transfer between the fibre and matrix. When higher fibre content of $10 \%$ was used, the damping peak shows the maximum value for almost all the frequency mode. It was observed that the effects of reinforcing poly-vinyl alcohol (PVA matrix with the palm kernel fibres caused the composites to be more flexible and easily deform due to high strain values and reduction of high resonant amplitude. In general, the mechanical properties of the developed composite showed variation at different test performed. This led to the conclusion that the material is most useful were strength to weight ratio is needed. The optimum percentage of fibre in epoxy resin to obtain the highest tensile properties was found at $10 \mathrm{vol} . \%$. It was also found that fibre, dispersion of fibre and interfacial adhesion between fibre-matrix can affect the mechanical properties of the composites.
\end{abstract}

\section{Introduction}

Composite materials are made from natural fibres or man-made materials obtained from the combination of two or more constituent materials with significantly different physical or chemical properties. Today these fibres are considered as environment friendly materials owing to their biodegradability and renewable characteristics. Natural fibres such as sisal, jute, coir, oil palm fibre have all been proved to be good reinforcement in thermoset and thermoplastic matrices [1]. Nowadays, the use of natural fibres reinforced composites is gaining popularity in automotive, cosmetic, and plastic lumber applications because it offers an economical and environmental advantage over traditional inorganic reinforcements and fillers [2]. The engineering of modern composites has had a significant impact on the technology of design and construction as a result therefore, by combining two or more materials we are able to tailor-make materials which are, stiffer and stronger than any other structural materials man has ever used. Concentration, usually measured as volume or weight fraction, determines the contribution of a single constituent to the overall properties of the composites. It is not only the single most important parameter influencing the properties of the composites, but also an easily controllable manufacturing variable used to alter its properties [3, 4]. Since the 1990s, natural fibre composites are emerging as realistic alternatives to glass-reinforced composites in many applications. Natural fibres represent a traditional class of renewable materials which, nowadays, are experiencing a great revival. In the latest years there have 
been many researches developed in the field of natural fibre reinforced plastics [5, 6, 7]. Krishnaprasad et al [8] indicated that the volume fraction of the natural fibre has a crucial effect on the composite strength where the strength of the composite raises linearly with the increase of volume fraction. Natural fibre composites such as hemp fibre-epoxy, flax fibre-polypropylene (PP), and china reed fibre-PP are particularly attractive in automotive applications because of lower cost and lower density [9, 10]. Poly-Vinyl Alcohol (PVA) resistance against organic solvents makes it adaptable for many applications, it has its low environmental impact, high chemical resistance, aqueous solubility, and biodegradability. Epoxy usually in liquid form contain monomers (consisting of simple molecules), which convert into polymers (complex cross-linked molecules) when the resin is cured. The resulting solid is called thermosets, which is tough, hard, insoluble and infusible [11]. Earlier studies by Bujang et al. [12] proved that coconut fibre can be used as effective reinforcement and bonded in polyester matrix. This paper however, addresses the characterization and performance of palm kernel fibre reinforced composite by analyzing the effect of fibre volume (\%) on the composite mechanical properties. The composites were obtained by compounding Poly-Vinyl Alcohol (PVA) matrix and fibres in a batch mixer to obtain a randomly oriented discontinue form. The choice of poly-vinyl alcohol (PVA) as a matrix is based on economic interest because it offers a very cheap resin, available with good mechanical properties and used in many applications such as transport, marine and sport.

\section{Materials and Method}

Basically three main tasks were carried out to achieve the objectives of study. The first task was the preparation of composite material by combining the Poly-Vinyl Alcohol (PVA) and palm kernel fibre reinforced with epoxy. Then it was continued by performing the mechanical tests and lastly the microstructural analysis. Basically, the palm kernel fibres was obtained from the palm kernel as showm in fig. 1 . After they had been abstracted as shown in fig. 2, the palm fibres were dried at $70^{\circ} \mathrm{C}$ to $80^{\circ} \mathrm{C}$ using drying oven. In order to avoid degradation factor, the fibres need to go through the treatment process. This process consists of immersing the fibres into 5\% Natrium Hydroxide $(\mathrm{NaOH})$ solution for 24 hours to remove the first layer of palm fibres. After that, the obtained fibres were washed abundantly with water to remove the $\mathrm{NaOH}$ before being dried again in furnace at $70^{\circ} \mathrm{C}$ to $80^{\circ} \mathrm{C}$ for next 24 hours. The fibres were then soaked into $5 \%$ of silane and $95 \%$ of methanol solution for 4 hour and dried at $70^{\circ} \mathrm{C}$ for next 24 hours curing time. After the drying process finished, the coconut fibres was inserted into the cutting machine to cut into smaller pieces. The advantage of this is that they can easily pour into the mixture of fibres and PVA in ASTM D638 Type 1 mould [13].

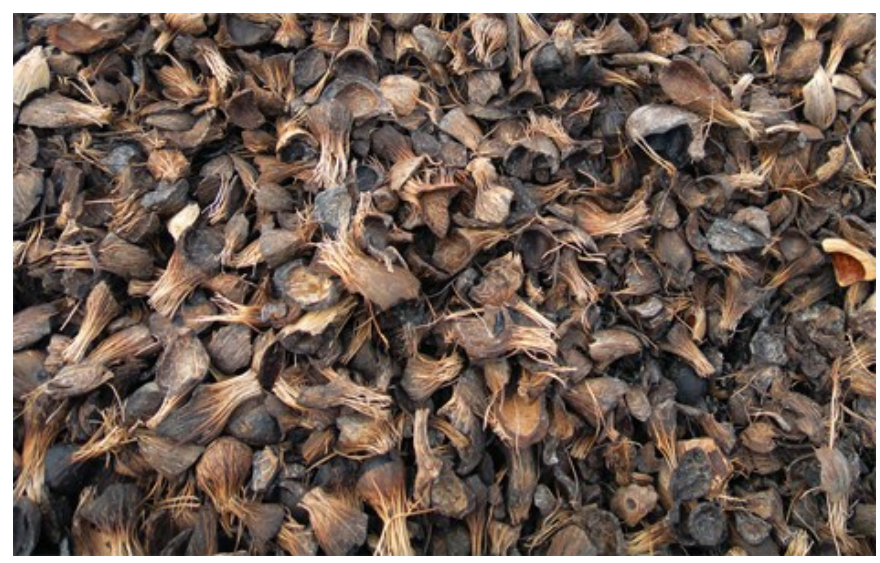

Fig. 1: Palm kernel shell with its fruit fibre 


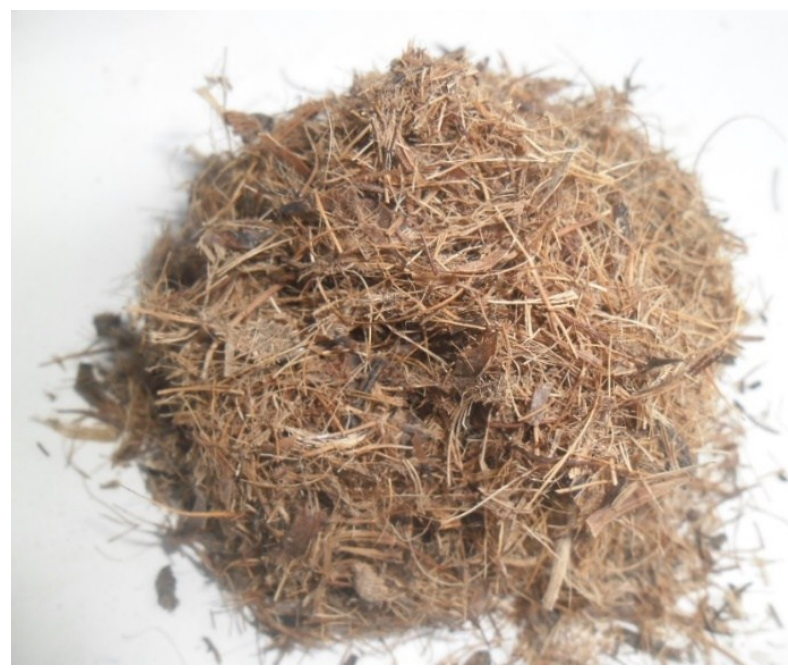

Fig. 2: Palm kernel shell fibre after separation

Composite Preparation. Composites having different fibres content were prepared by varying the fibres volume from $4 \%$ to $12 \%$. In the first process of preparing the composite, a release agent was used to clean and dry the mould before the PVA can be laid up on the mould. The PVA was then mixed uniformly with the palm kernel fibres and epoxy by using a special brush in the mixed container. The mixture was poured carefully into the moulds and flattened appropriately by using the roller before being dried. When pouring, pressure was applied from top and the mould was allowed to cure at room temperature for 72 hours. After the composites were fully dried, they were separated off from the moulds. The samples for the composites consists of the following percentage as shown in Table 1.

Table 1: Percentage weight proportion of the samples

\begin{tabular}{|l|l|l|l|}
\hline Sample & $\begin{array}{l}\text { Palm kernel fibre } \\
(\%)\end{array}$ & Epoxy (\%) & $\begin{array}{l}\text { Poly Vinyl alcohol } \\
(\%)\end{array}$ \\
\hline 1 & 4 & 40 & 90 \\
\hline 2 & 6 & 50 & 60 \\
\hline 3 & 8 & 60 & 60 \\
\hline 4 & 10 & 70 & 40 \\
\hline 5 & 12 & 45 & 50 \\
\hline
\end{tabular}

The measured quantity for sample 1 were mixed together. During the mixing, care was taken when stirring to minimize air been entrapped in the mixture. During the application of pressure some of the epoxy and poly-vinyl alcohol squeezed out. Care was taken in order to achieve a constant thickness of the sample to be manufactured. The same process was repeated for other samples 2, 3, 4, and 5 .

Tensile testing is the most common mechanical testing for determining the physical properties of materials such as strength, ductility, toughness, elastic modulus, and strain hardening. The tests consist of applying a constant strain on the fibres and measure the load. Universal Testing Machine was used with strain speed of $10 \mathrm{~mm} / \mathrm{min}$. The distance between clips was defined of $115 \mathrm{~mm}$. Four specimens were prepared in the study for each percentage of fibres in order to get more accurate results. As described in American Standard Testing and Measurement (ASTM) method D638 Test for tensile properties were determined. Each tensile specimen was positioned in the tester and then subjected to tensile load, as the specimen stretched the computer generated the graph as well as all the desired parameters until the specimen fractured. 


\section{Results and Discussion}

From the physical appearance of the composites, the texture varies according to their weight percentage variation. Sample 1 show a composite rich in epoxy and poly-vinyl alcohol while sample 5 displays a composite rich in palm kernel fibre.

Hardness Test. The Palm Kernel Fibre have significant effect on the hardness of the composite. Fig. 3 shows the hardness values of the composite samples. It was observed that the hardness value increases as the percentage Palm Kernel Fibre addition increases. This is due to increase in the percentage of the hard and brittle phase of the ceramics body in the PVA matrix. From the hardness test result, sample 5 has the highest hardness value. It is observed that as the reinforcement increases the hardness increases and the maximum value of $8.63 \mathrm{HV}$ was obtained for sample 5 composite prepared with $12 \%$ Palm Kernel Fibre. A substantial improvement in hardness values was obtained in the reinforced polymer matrix. This may be attributed to its inherent properties such as high strength and high modulus. This can be as a result of the $12 \%$ palm kernel shell fibre present in it. Sample 2 with $6 \%$ palm kernel shell fibre also displayed a likely manner as sample 5. This could be attributed to the fact that the ratio of the poly vinyl alcohol to epoxy available in them is appreciable and are very close.

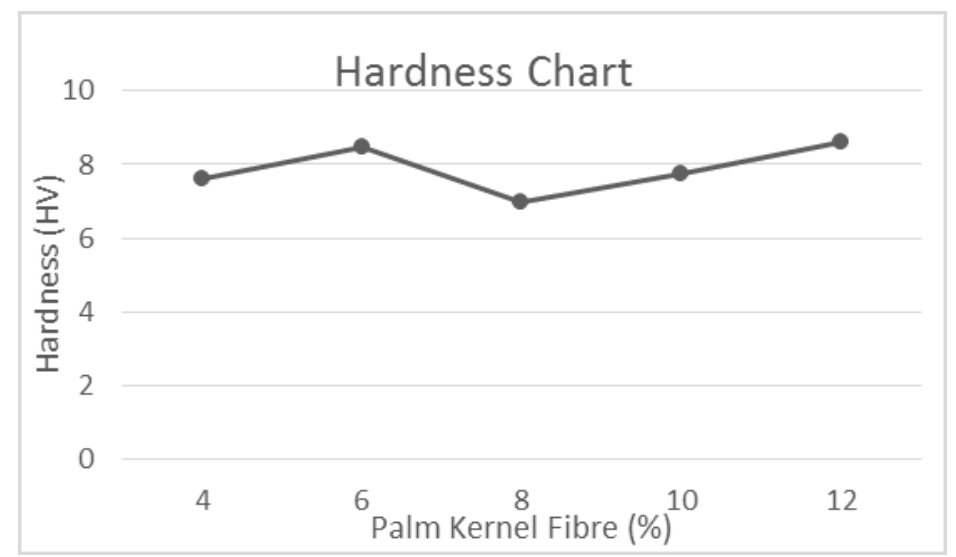

Fig. 3: Hardness value versus $\%$ of palm kernel fibre

Impact Test. Fig. 4 illustrates the Izod impact strength results of palm kernel fibre rein-forced with poly-vinyl alcohol and epoxy. It is clear from the figure that the impact strength at failure increased from sample 1 to 3 and then decreased from 4 to 5 with increase in palm kernel fibre content within the composite. This is mainly due to the reduction of elasticity of material due to particles addition and thereby reducing the deformability of matrix. An increase in concentration of palm kernel fibre reduces the ability of matrix to absorb energy and thereby reducing the toughness, so impact strength decreases. The sample with $12 \%$ volume fraction palm kernel fibre in the matrix has the lowest impact energy of $3.7 \mathrm{~J}$. The reduction in impact energy at failure with increasing palm kernel fibre might be due to the decreased deformability of a rigid interface between the fibre and polyvinyl alcohol (PVA). It is evident that the developed composites may have lower area under the stress-strain curves and therefore poor toughness. This could be the predictable result, because rigid ceramics body such as palm kernel fibre act as barriers against the mobility of dislocations. Therefore, by increasing the content of coconut shell powder, the rate of work hardening increases and this would lead to a decrease in toughness values. It is observed that sample 3 composite with equal ratio of epoxy and poly vinyl alcohol has highest impact energy of $4.3 \mathrm{~J}$. 


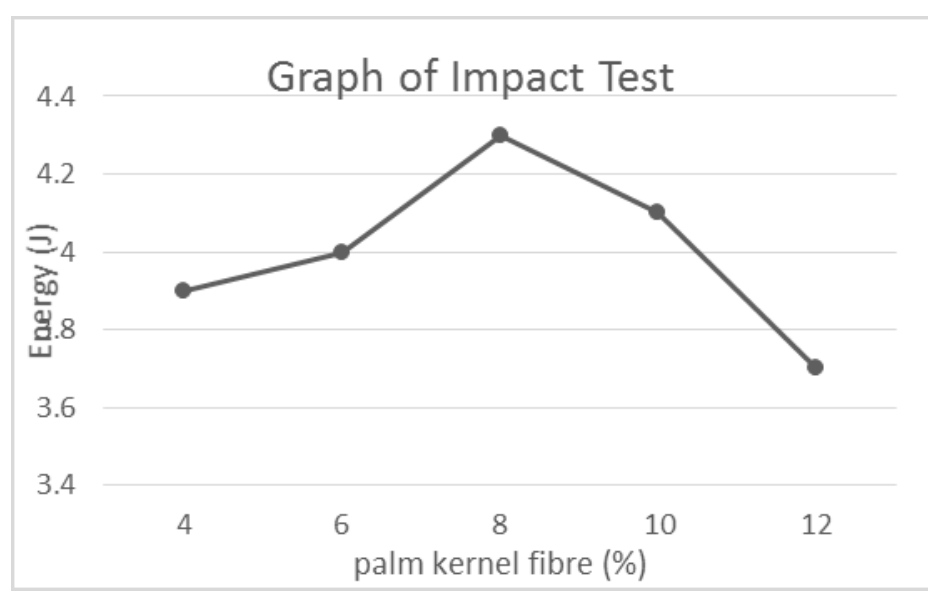

Fig. 4: Impact strength versus \% of palm kernel fibre

Flexural Test. Fig. 5 illustrates the flexural test result. It is observed that sample 1 performed better under flexural test compared to other samples. This can be attributed to the high percentage of polyvinyl alcohol in the matrix compared to other materials present in it. As the percentage of poly-vinyl is reduced and epoxy is increased, the flexural strength decreased. The flexural graph shows that sample 3 possessed poorest flexural ability. Sample 4 and 5 showed an increase in their flexural strength.

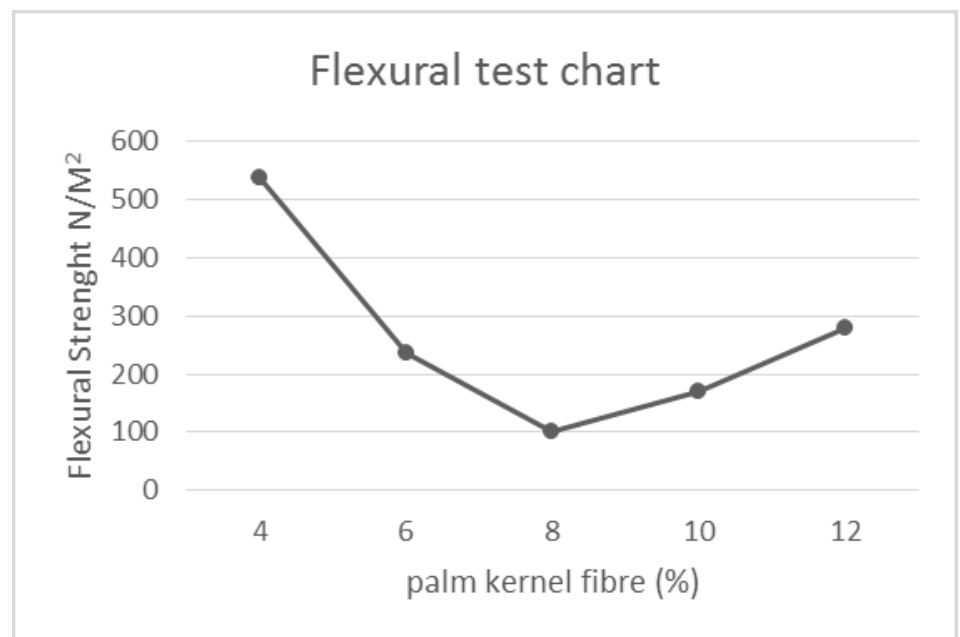

Fig. 5: Flexural strength versus \% of palm kernel fibre

The Tensile Properties of the Composites. From Fig. 6, sample 4 with highest epoxy percentage at $70 \%$ displayed the maximum tensile stress at $4.77510 \mathrm{Mpa}$ with the least tensile strain at 0.0377 $\mathrm{mm} / \mathrm{mm}$. Sample 5 having the least epoxy percentage at $45 \%$ displayed the least tensile stress at $0.78645 \mathrm{Mpa}$. Sample 1 has tensile stress at 3.23305 Mpa while having the maximum tensile strain at $0.178 \mathrm{~mm} / \mathrm{mm}$. This could be seen that the level of poly vinyl alcohol present also affect the strain values of the composites. 


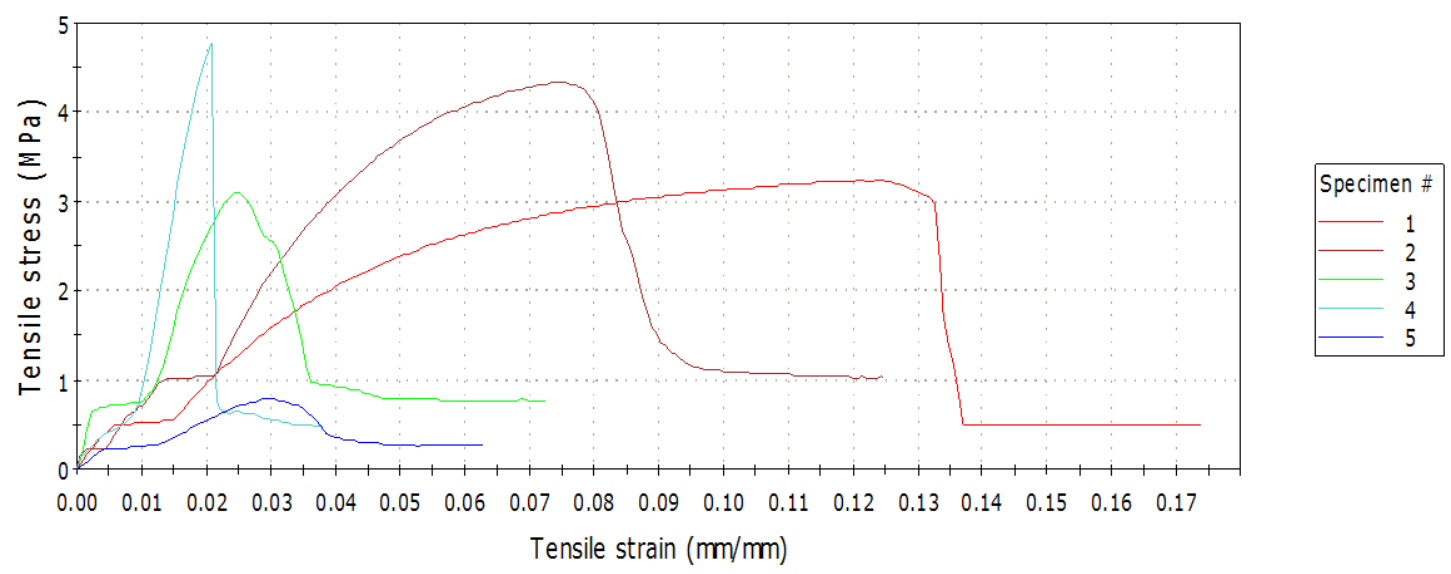

Fig. 6: Tensile properties of the composites

The tensile strength increased with increasing palm kernel fibres content up to $10 \%$ but decreased when the palm kernel fibres content was above $12 \%$ due to the aggregation in the composites as shown in Fig. 6.

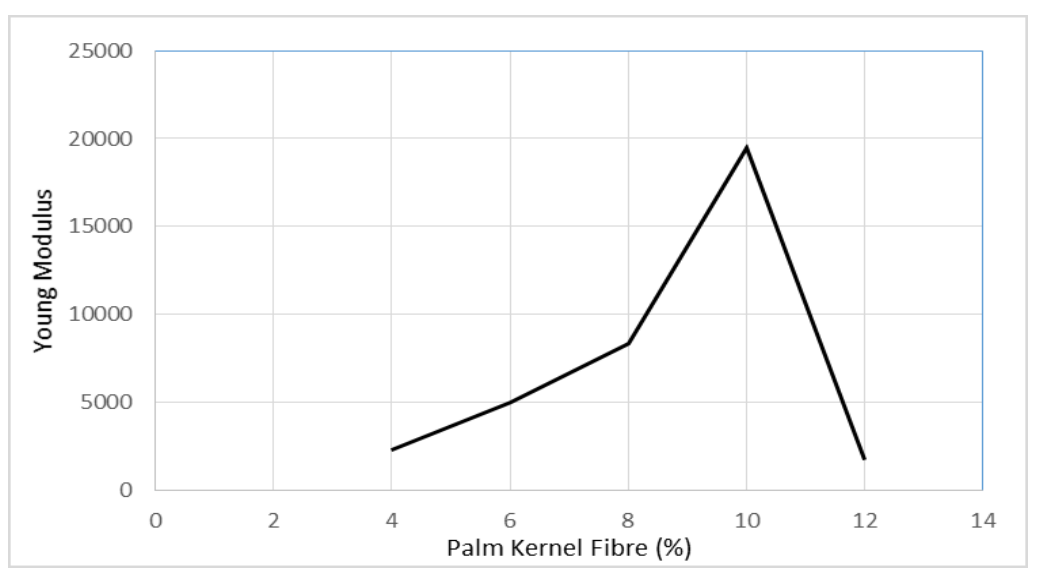

Fig. 7: Young modulus of each percentage of palm kernel fibre

From Fig. 7 by the incorporation of palm kernel fibres, the Modulus Young, E value of composites increased for the fibres up to $10 \%$ volume but on further increasing the fibres content, the value decreased. The minimum value of Young Modulus was obtained at a sample 5 with fibres volume of $12 \%$ which specify ineffective stress transfer between the palm kernel fibres and poly vinyl alcohol matrix.

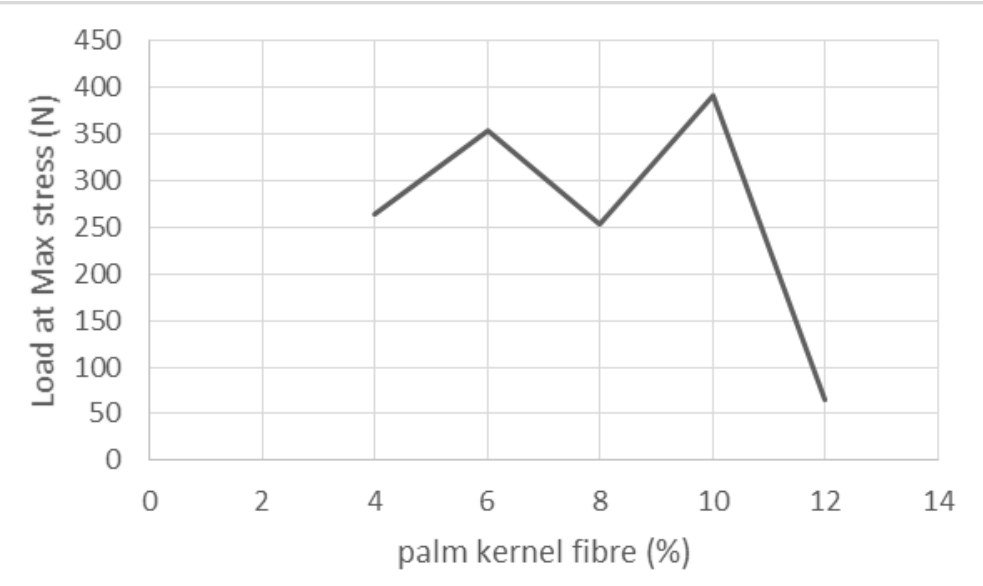

Fig. 8: Load at maximum stress versus $\%$ of palm kernel fibre 
The result in Fig. 8 indicates that the load at maximum tensile stress is affected with increase in palm kernel fibre volume. The dispersion of palm kernel fibre and interfacial adhesion between fibre and epoxy caused the load at maximum tensile stress of $10 \%$ palm kernel fibre reinforced composites containing $70 \%$ epoxy to show a higher value than the other palm kernel fibre reinforced composites.

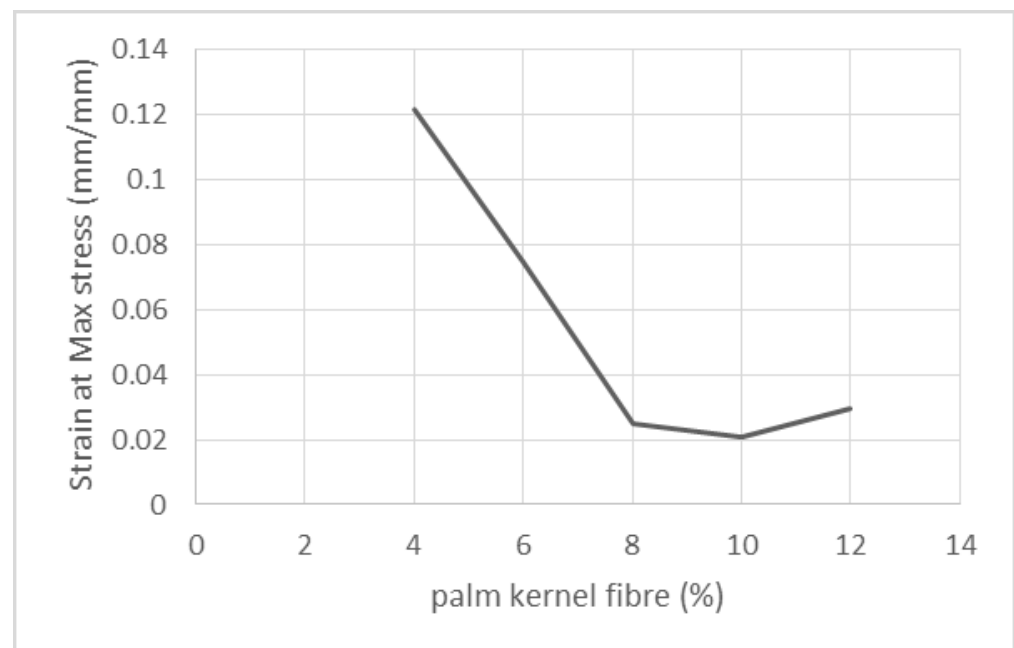

Fig. 9: Tensile strain at maximum stress versus $\%$ of palm kernel fibre

Fig. 9 shows that strain at maximum stress steadily decreases with increasing fibres content. With a further increase in fibre loading, the strain at maximum stress increased and reached a maximum at a fibre loading of $12 \%$. At low volumes of palm kernel fibre, less than $10 \%$ in PVA, the strains of the composites were elevated, indicating well toughening effects.

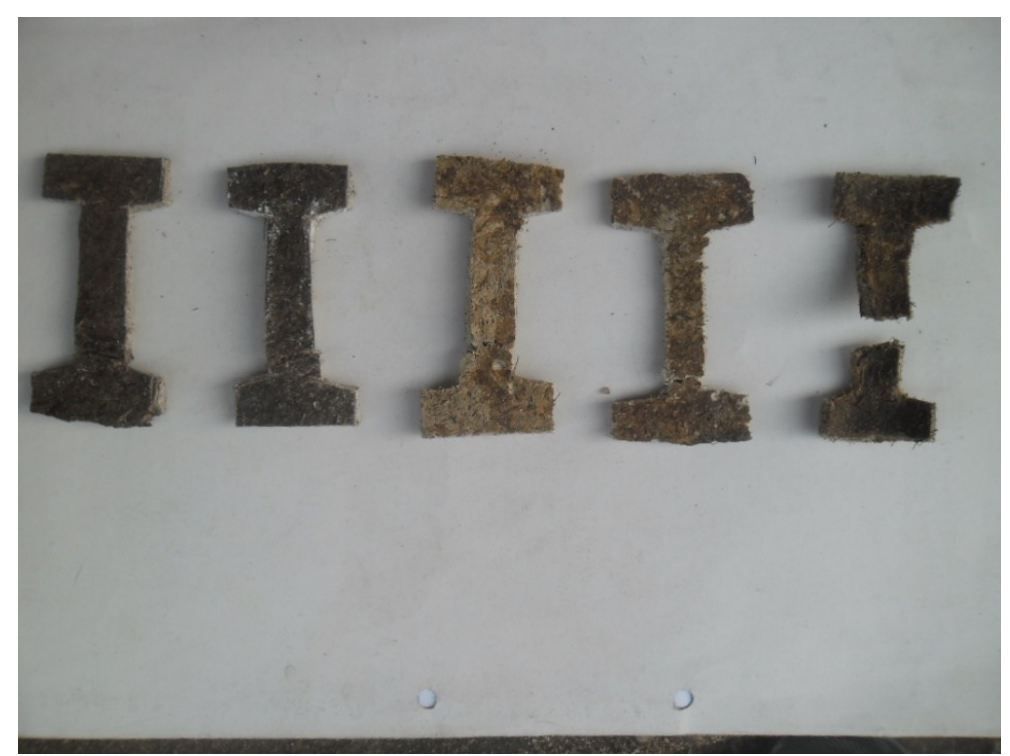

Fig. 10: Specimen for tensile test

The Microstructure. From the images in Fig. 11 to 15 gotten of the micro-structure, it is clear that the palm kernel fibre has a uniform bond between the epoxy and poly-vinyl alcohol, although there exist some small air vents in the mixture. Fig. 11 shows pebble-like PVA particles. In fig. 12 welldispersed bright dots and pebble on the surface of PVA composite were witnessed. No large palm kernel fibre agglomerates and good adhesion between PVA and fibre are seen. The images in fig. 14 showed that palm kernel fibre was uniformly distributed in PVA. These well-dispersed palm kernel fibre indicates the strong palm kernel fibre - PVA bonding. The strong bonding contributed to the excellent mechanical properties of the composites. 


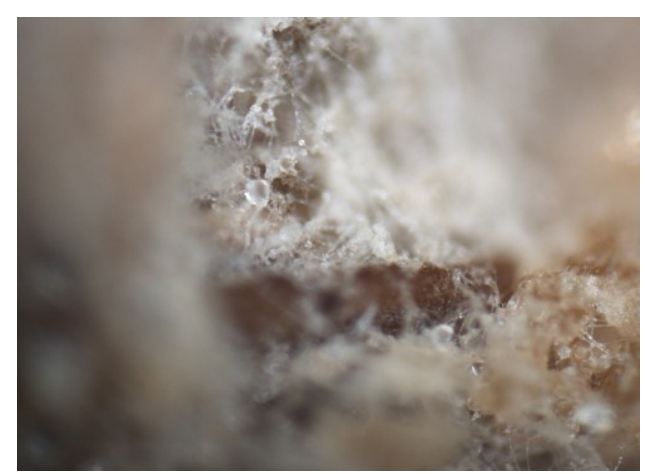

Fig. 11: Sample 1

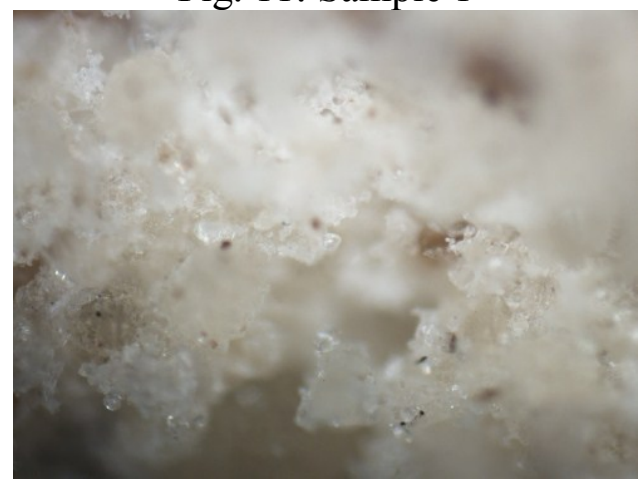

Fig. 12: Sample 2

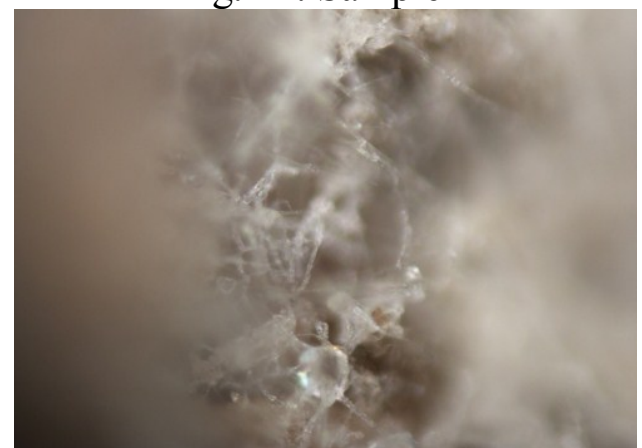

Fig 13: Sample 3

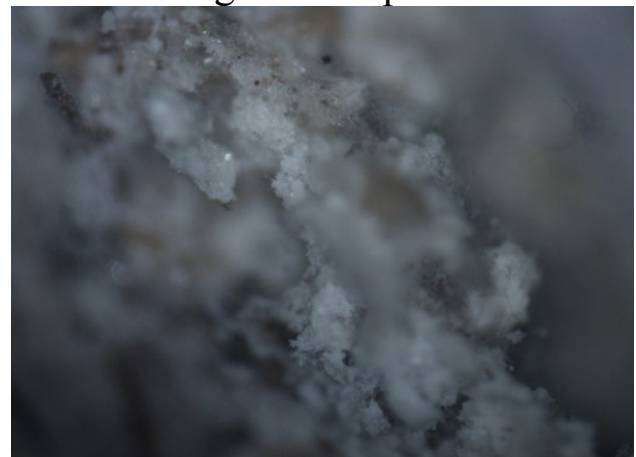

Fig. 14: Sample 4

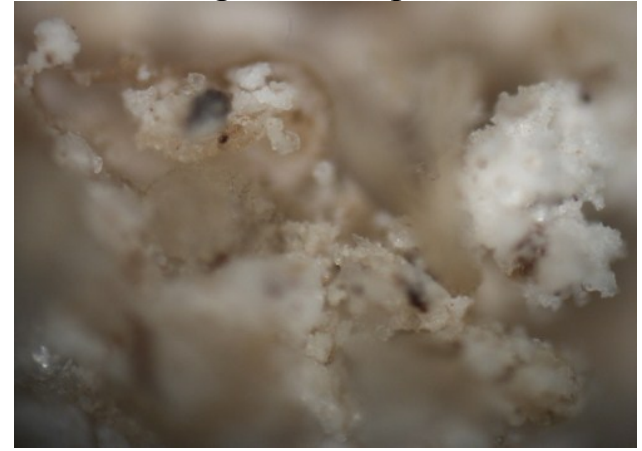

Fig. 15: Sample 5 
Density Test. A clean sample was weighed accurately in air using an automatic density electronic balance model: JA5003J. The density of the composites was calculated and the graph of the results is shown in Fig. 18. From the graph, it is observed that the particle samples for density 1, 3 and 5 increases, while 2 and 4 decreases. This is probably because of the different percentage mixtures of palm-kernel with epoxy and poly-vinyl alcohol of each sample.

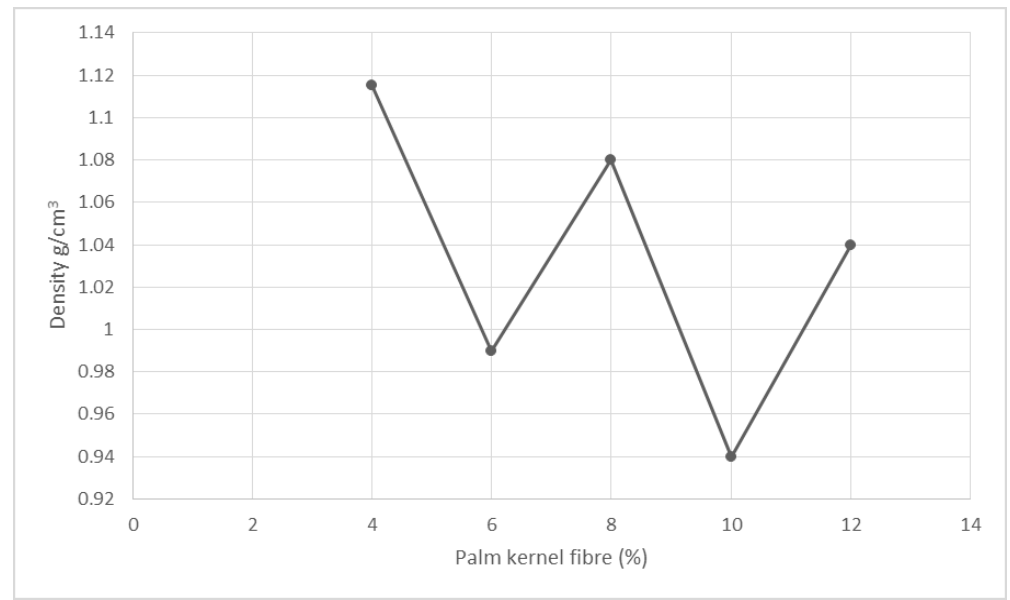

Fig. 18: Density Test

\section{Conclusions}

The research was carried out to investigate the mechanical analysis of randomly oriented mixed palm kernel fibres reinforced epoxy and poly-vinyl alcohol composite. PVA was successfully integrated with the epoxy and palm kernel fibre to form composites. The effect of palm kernel fibres volume on mechanical properties of composite were studied. The results showed that the mechanical properties are greatly dependent on the percentage volume of fibres in the composite. The results of mechanical properties testing showed that the Young's modulus and the hardness of composites were improved with the increment of fibre volume fraction. Sample 4 having a $10 \%$ volume of palm kernel fibres recorded the best tensile result. However the increase of palm kernel fibres up to $12 \%$ lowered the Young's modulus and the hardness of the composites. The hardness value of the composites increases which is attributed to the increase in the ratio of palm kernel fibre of each samples. The microstructure observation reveals that fibre has a uniform bond between the epoxy and poly-vinyl alcohol, although there exist some small air vents in the mixture. This shows that palm kernel fibre has a uniform bond between the epoxy and poly-vinyl alcohol. The flexural strength of the composites starts to drop as the percentage of poly-vinyl is reduced and epoxy is increased. The impact test shows that the composite with equal ratio of epoxy and polyvinyl alcohol presented a significant increase in impact strength.

\section{Acknowledgement}

The authors wish to acknowledge the support given by Alo Francis of Materials and Metallurgical Engineering Department, Obafemi Awolowo University, Ife for providing facilities for this research. Also, the authors would like to thank the authors whose references are used for this research. 


\section{References}

[1] J. van der Geer, J.A.J. Hanraads, R.A. Lupton, The art of writing a scientific article, J. Sci. Commun. 163 (2000) 51-59.

[1] M. S. Abdelmouleh, M.N. Boufi, A.P. Belgacem, A.B. Duarte, A. G. Salah, Modification of cellulosic fibres with functionalized silanes: Effect of the fibre treatment on the mechanical performance of cellulose-thermoset composites. Journal of Applied Polymer Science, (2005)

[2] M. F. Ashby, Composites: Resins, Fillers, Reinforcements Philosophical Transactions of the Royal Society of London, (1987) A322: 393. Business Communications Co, Inc.

[3] M. Chinomso, O. I Igwe. Properties of Oil Palm Empty Fruit Bunch Fibre Filled High Density Polyethylene. International Journal of Engineering and Technology Vol.3 (6), (2012) 458-471

[4] A. M. Edeerozey, H. Md Akil, A. B. Azhar, M. I. Zainal, Chemical modification of kenaf fibres, Materials Letters; 61, (2006) 2023-2025.

[5] N.A. Ibrahim, K.A. Hadithon, K. Abdan, Effect of fibre treatment on mechanical properties of kenaf-Ecoflex composites. Journal of Reinforced Plastics and Composites; 29, (2010) 29212198.

[6] K. B. Vijay, S. Dharminder, Research Work On Composite Epoxy Matrix \& Ep Polyester Reinforced Material International Journal of Engineering Research \& Technology (IJERT) ISSN: 2278-0181 Vol. 2 Issue 1. (2013)

[7] R. Kumar, M.K Yakubu, R.D. Anandjiwala, Biodegradation of flax fibre reinforced poly(lactic acid). Express Polymer Letters; 4, (2010) 423-230.

[8] R. Krishnaprasad, N.R Veena, H. JMaria, R. Rajan, M. Skrifvars, K. Joseph, Mechanical and thermal properties of bamboo microfibril reinforced polyhydroxybutyrate bio-composites. Journal of Polymers and the Environment; 17, (2009) 109-114.

[9] A. Magurno, Vegetable fibres in automotive interior components. Die Angew Makromol Chem; 272, (1999) 99-107.

[10] P. Mukhopadhyay, Emerging trends in plastic technology. Plastics Engineering; 58, (2002) 2835.

[11] K. Oksman, M. Skrifvars, J.F. Selin, Natural fibres as reinforcement in polylactic acid (PLA) composites. Composites Science and Technology; 63, (2003) 1317-1324.

[12] I. Z. Bujang, M. K. Awang, A. E. Ismail, Study on the dynamic characteristic of Coconut fibre reinforced composites, Regional Conference on Engineering Mathematics, Mechanics, Manufacturing \& Architecture (EM*ARC) (2007)

[13] M.E. Turtle, Structural Analysis of Polymeric Composite Materials. New York: Marcel Dekker Inc. (2004) 1-41. 